\title{
Inconsistency in precipitation measurements across the Alaska-Yukon border
}

\author{
L. Scaff ${ }^{1}$, D. Yang ${ }^{2}$, Y. Li ${ }^{1}$, and E. Mekis ${ }^{3}$ \\ ${ }^{1}$ Global Institute for Water Security and School of Environment and Sustainability, University of Saskatchewan, \\ Saskatoon, Saskatchewan, Canada \\ ${ }^{2}$ National Hydrology Research Center, Environment and Climate Change Canada, Saskatoon, Saskatchewan, Canada \\ ${ }^{3}$ Climate Research Division, Science and Technology Branch, Environment and Climate \\ Change Canada, Toronto, Ontario, Canada
}

Correspondence to: Y. Li (yanping.li@usask.ca)

Received: 8 June 2015 - Published in The Cryosphere Discuss.: 16 July 2015

Revised: 16 November 2015 - Accepted: 6 December 2015 - Published: 21 December 2015

\begin{abstract}
This study quantifies the inconsistency in gauge precipitation observations across the border of Alaska and Yukon. It analyses the precipitation measurements by the national standard gauges (National Weather Service (NWS) 8 in. gauge and Nipher gauge) and the bias-corrected data to account for wind effect on the gauge catch, wetting loss and trace events. The bias corrections show a significant amount of errors in the gauge records due to the windy and cold environment in the northern areas of Alaska and Yukon. Monthly corrections increase solid precipitation by $136 \%$ in January and $20 \%$ for July at the Barter Island in Alaska, and about $31 \%$ for January and $4 \%$ for July at the Yukon stations. Regression analyses of the monthly precipitation data show a stronger correlation for the warm months (mainly rainfall) than for cold month (mainly snowfall) between the station pairs, and small changes in the precipitation relationship due to the bias corrections. Double mass curves also indicate changes in the cumulative precipitation over the study periods. This change leads to a smaller and inverted precipitation gradient across the border, representing a significant modification in the precipitation pattern over the northern region. Overall, this study discovers significant inconsistency in the precipitation measurements across the USA-Canada border. This discontinuity is greater for snowfall than for rainfall, as gauge snowfall observations have large errors in windy and cold conditions. This result will certainly impact regional, particularly cross-border, climate and hydrology investigations.
\end{abstract}

\section{Introduction}

It is known that discontinuities in precipitation measurements may exist across the national boundaries because of the different instruments and observation methods used (Nitu and Wong, 2010; Sanderson, 1975; Sevruk and Klemm, 1989; Yang et al., 2001). For instance, the National Weather Service (NWS) 8 in. gauge is used for precipitation measurements in the United States (USA), and the Nipher snow gauge has been used in Canada for decades. Different instruments have also been used in various observational networks within the same country. In the synoptic network, the Type-B rain gauge and Nipher gauge are the standard manual instruments for rain and snow observations in Canada (Mekis and Vincent, 2011; Metcalfe and Goodison, 1993), and recently the Geonor automatic gauges have been installed.

Instruments also change over time at most operational networks, resulting in significant breaks in data records. It has been realized that combination of regional precipitation records from different sources may result in inhomogeneous precipitation time series and can lead to incorrect spatial interpretations (Yang et al., 2005). Efforts have been reported to examine the precipitation discontinuity within a country (Groisman and Easterling, 1994; Sanderson, 1975). Leeper et al. (2015) found that the US Cooperative Observer Program (COOP) Network stations reported slightly more precipitation overall $(1.5 \%)$, with network differences varying seasonally. The COOP gauges were sensitive to wind biases, particularly over winter when COOP observed $(10 \%)$ less precipitation than the US Climate Refer- 


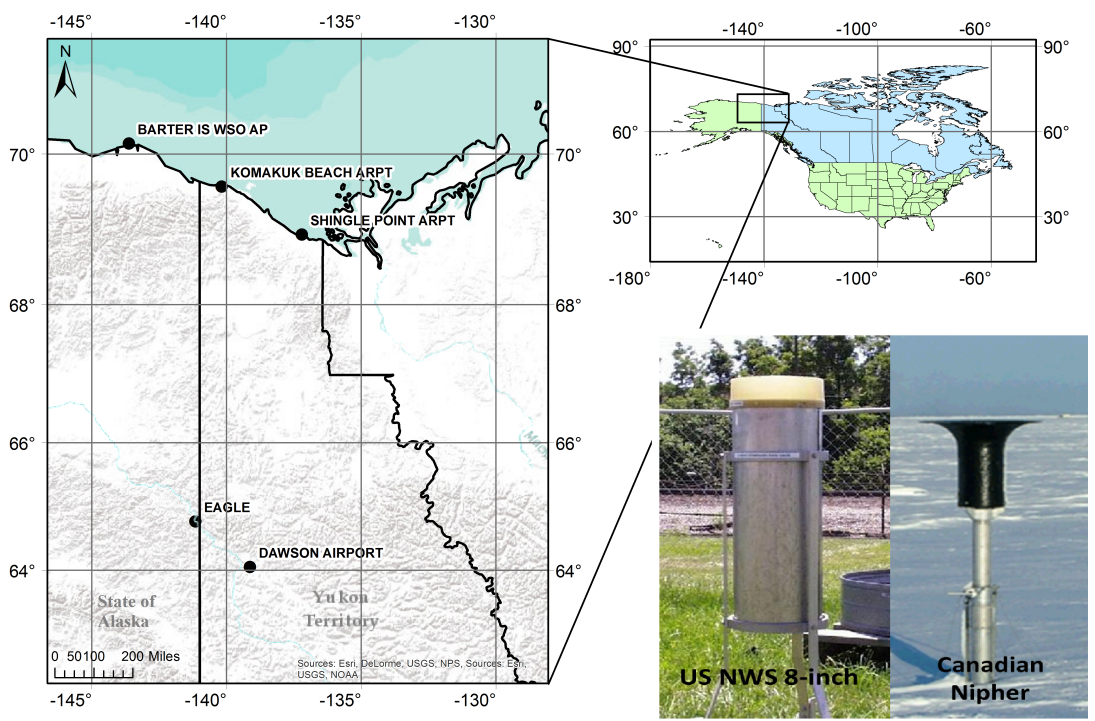

Figure 1. Study areas and locations of selected climate stations, and photos of the national standard gauges, NWS 8 in. gauge (left) and the Nipher snow gauge (right), respectively, for the USA and Canada.

ence Network (USCRN). Conversely, wetting and evaporation losses, which dominate in summer, were sources of bias for USCRN. Mekis and Brown (2010) developed adjustment method to link the Nipher gauge and ruler snowfall measurements over Canada. Yang and Simonenko (2013) compared the measurements among six Russian Tretyakov gauges at the Valdai experimental station and reported differences of less than $5-6 \%$ for the study period. These results are useful to determine the homogeneity of precipitation data collected by a standard gauge within the national and regional networks.

Many studies show that the national standard gauges, including the Canadian Nipher and US $8 \mathrm{in}$. gauges, undermeasure precipitation, especially for snowfall (Goodison, 1981; Goodison et al., 1998; Yang et al., 1995, 1998a, 1999). Compatibility analysis of precipitation measurements by various national gauges suggests little difference (less than $5 \%$ ) for rainfall observations, but a significant discrepancy (up to $110 \%$ ) for snowfall measurements (Yang et al., 2001). For instance, the experimental data from Valdai show that the US 8 in. gauge at Valdai systematically measured $30-50 \%$ less snow and mixed precipitation than the Canadian Nipher gauge (Yang et al., 2001). This difference in national gauge catch has introduced a significant discontinuity in precipitation records across the USA-Canada border, particularly in windy and cold regions. Differences in the snow measurements across the USA-Canada border have also been noticed in other studies as problematic for producing gridded products and for developing precipitation input for basin hydrological investigations (Šeparović et al., 2013; Zhao et al., 2010).

Although Yang et al. (2001) compared the relative catch of many national standard gauges, little has been done to address the inconsistency of precipitation records across the national borders. This is an important issue, since most regional precipitation data and products have been compiled and derived from the combination of various data sources, assuming these data and observations were compatible across the borders and among the national observational networks. Simpson et al. (2005) studied temperature and precipitation distributions over the state of Alaska (AK) and west Yukon (YK), and documented precipitation increase from north to south. They also report differences in mean monthly precipitation across the Alaska-Yukon border, i.e. about 5-15 mm in central-east Alaska and $15-40 \mathrm{~mm}$ in central-west Yukon. Jones and Fahl (1994) found a weak gradient in annual precipitation across the AK-YK border, including the headwaters of the Yukon River. Other studies also discuss precipitation distribution and changes over the Arctic regions (Legates and Willmott, 1990; Serreze and Hurst, 2000; Yang et al., 2005).

The objective of this work is to examine the inconsistency in precipitation measurements across the border between Alaska and Yukon. We analyse both gauge-measured and bias-corrected monthly precipitation data at several climate stations across the border, and quantify the changes in precipitation amounts and patterns due to the bias corrections. We also calculate the precipitation gradients across the border and discuss precipitation distribution for the warm and cold seasons. The methods and results of this study are useful for cold-region climate and hydrology investigations and applications. 
Table 1. Station information and climate summary.

\begin{tabular}{|c|c|c|c|c|c|c|c|c|c|c|c|c|c|}
\hline \multirow[t]{2}{*}{$\begin{array}{l}\text { ID } \\
\text { WMO }\end{array}$} & \multirow[t]{2}{*}{ Country } & \multirow[t]{2}{*}{ Station name } & \multicolumn{3}{|c|}{ Location } & \multicolumn{2}{|c|}{$\begin{array}{c}\text { Data } \\
\text { period }\end{array}$} & \multirow{2}{*}{$\begin{array}{c}\text { Measurement } \\
\text { device }\end{array}$} & \multicolumn{5}{|c|}{ Annual means } \\
\hline & & & Lat $\left({ }^{\circ}\right)$ & Lon $\left(^{\circ}\right)$ & Altitude (m) & Start & End & & $\begin{array}{r}\text { Precipitation } \\
(\mathrm{mm})\end{array}$ & $\begin{array}{r}\text { Missing } \\
\text { precipitation } \\
\text { data }(\%)\end{array}$ & $\begin{array}{l}\text { Min. } \\
\text { temp. } \\
\left({ }^{\circ} \mathrm{C}\right)\end{array}$ & $\begin{array}{l}\text { Max. } \\
\text { temp. } \\
\left({ }^{\circ} \mathrm{C}\right)\end{array}$ & $\begin{array}{r}\text { Wind } \\
\text { speed } \\
\left(\mathrm{m} \mathrm{s}^{-1}\right)\end{array}$ \\
\hline 700860 & USA & Barter IS WSO AP & 70.13 & -143.63 & 11 & 1978 & 1988 & US 8 in. unshielded & 155 & 0.3 & -27.1 & 4.6 & 4.0 \\
\hline 719690 & CA & Komakuk Beach ARPT & 69.58 & -140.18 & 7 & 1978 & 1988 & Nipher Type-B gauge & 191.8 & 2.9 & -27.5 & 7.4 & 3.9 \\
\hline 719680 & $\mathrm{CA}$ & Shingle Point ARPT & 68.95 & -137.21 & 49 & 1978 & 1988 & Nipher Type-B gauge & 302 & 6 & -26.6 & 10.6 & 3.4 \\
\hline 701975 & USA & Eagle & 64.78 & -141.16 & 268 & 2006 & 2013 & US 8 in. unshielded & 247 & 0.2 & -22.7 & 15.5 & 0.9 \\
\hline 719660 & $\mathrm{CA}$ & Dawson Airport & 64.05 & -139.13 & 369 & 2006 & 2013 & Nipher Type-B gauge & 258 & 0.6 & -25.8 & 15.9 & 1 \\
\hline
\end{tabular}

\section{Study area, data and methods}

The study areas include the northern and central regions of Alaska and Yukon. We choose five climate stations across the Yukon-Alaska border, which use the national standard gauges (NWS 8 in. gauge and the Canadian Nipher gauge) for precipitation observations (Fig. 1). These stations can be classified into two groups. The first group, three stations about $150 \mathrm{~km}$ apart, is the northern region along the coast of the Beaufort Sea, with the Barter Island station in Alaska and Komakuk and Shingle Point stations in Yukon. The second group is in the central part of the region: the Eagle station in Alaska and Dawson station in Yukon, about $130 \mathrm{~km}$ apart.

The three northern stations selected for this study are located north of the Brooks Range. The approximate distances to the mountain edge are $100 \mathrm{~km}$ for the Barter Island station, $90 \mathrm{~km}$ for Shingle Point station, and $150 \mathrm{~km}$ for the Komakuk station. Both stations in Yukon are along the shoreline, and the station in Alaska is an island site, very close to the coastline. The altitudes of the stations range from 7 to $49 \mathrm{~m}$ a.s.l. According to Manson and Solomon (2007), the summer storm tracks are usually from the northwest, coming from the open water in the Beaufort Sea, and are the greatest contributor to annual precipitation. The storms are obstructed by the Brooks Range once moving inland. The weather patterns in the surrounding of the stations might be affected by the mountains, but the stations are not separated by the Brooks Range. Given this setting, it is expected to see little impact of mountain range on the precipitation process and distribution along the relatively flat coastline.

These stations have been operated by the NWS and Environment Canada (EC) since the early 1970s. The observations have been done according to the national standards of the USA and Canada. The detailed information for these stations is given in Table 1, such as the location; period of measurement used for this work; instrument types for precipitation observations; and a climate summary for yearly temperature, precipitation, and wind speed.

Yang et al. (2005) have developed a bias-corrected daily precipitation data set for the northern regions above $45^{\circ} \mathrm{N}$. The source data are acquired from the National Centers for Environmental Information (NCEI), i.e. a global daily surface data archive for over 8000 stations around the world (https://www.ncdc.noaa.gov/data-access/quick-links\# ghen). To focus on the high-latitude regions, a subset of the global daily data, about 4000 stations located north of $45^{\circ} \mathrm{N}$ with data records longer than 20 years during 1973-2003, has been created. Yang et al. (2005) applied a consistent procedure derived from the WMO Solid Precipitation Intercomparison (SPICE; Goodison et al., 1998), using wind speed, temperature, and precipitation as inputs (Yang et al., 1998b, 2005). They quantify the precipitation gauge measurement biases for the wind-induced undercatch, wetting losses, and trace amount of precipitation. For the US stations, wind data from the standard height were reduced to the gauge level of the NWS 8 in. gauge (standard height is $1 \mathrm{~m}$ ). Wind speeds and directions were measured at the Canadian climatic network; the same approach was applied to estimate the wind speed at the gauge height (standard height is $2 \mathrm{~m}$ ) on precipitation days. The corrections were done only for those stations with wind observations. Unfortunately there are many stations in the USA without wind information, and this is a challenge to gauge bias corrections.

This study uses the updated (until 2013) monthly precipitation, temperature and wind speed data from Yang et al. (2005) for the selected AK and YK stations (Table 1). The selected data periods range from 7 to 10 years for the stations, which is considered long enough to examine precipitation patterns in these regions. Missing records affect regional climate data analyses. In this study, a threshold of $0^{\circ} \mathrm{C}$ of monthly temperature has been used to determine the cold and warm months for snow and rain. Mixed precipitation has not been classified separately. The frequency of missing values was calculated when the bias correction was made in Yang et al. (2005). Any month with fewer than 20 days $(\sim 30 \%)$ of measurements is excluded from data analysis. Statistical methods to compare the measured and corrected monthly and yearly precipitation data across the selected border station pairs is used to analyse these data. It also carries out regression analysis on monthly precipitation records and calculates the cumulative precipitation amounts to derive the double mass curves (DMCs) over the study period. The DMC is a useful tool to evaluate the consistency of observation records over space and time (Searcy and Hardison, 1960). Some typical issues of observations that DMCs can identify include changes in the station location and in- 

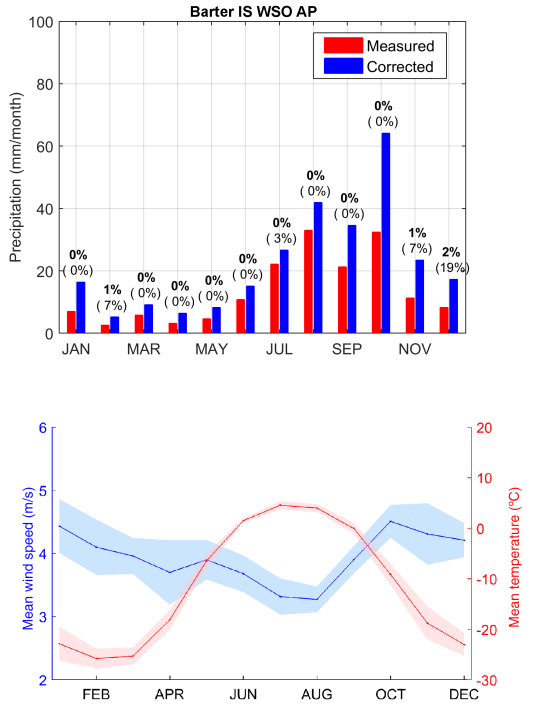
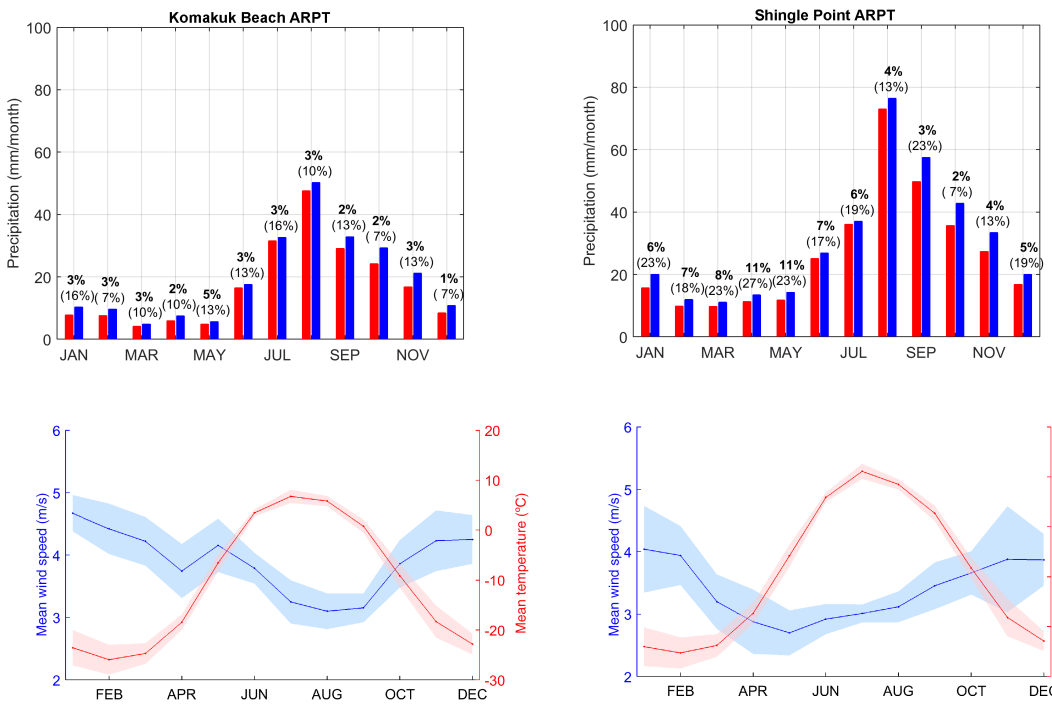

Figure 2. Monthly mean precipitation at three stations during 1977-1988 (upper panels) and corresponding monthly mean wind speed and air temperature (bottom panels). Shadows represent the $95 \%$ confidence interval for the temperature and wind speed. The percentages above the bars represent the missing data for the corresponding time step. The bold percentage is the monthly mean, and the one in the parentheses is the maximum missing value in the study period.

struments or sensors. A reference station is needed for DMC analyses. In this study, the DMC has been applied without a reference station to mainly detect any shifts between the observed and corrected precipitation. Through the data analyses and comparisons with other studies, we document the spatial and temporal variations of bias corrections across the border stations. We also determine the precipitation gradients across the border and examine the changes, due to the bias corrections of the US and Canadian gauge data, in precipitation distributions on both seasonal and yearly timescales.

\section{Results}

Based on the analyses of the measured precipitation $\left(P_{\mathrm{m}}\right)$ and corrected precipitation $\left(P_{\mathrm{c}}\right)$ data, this section presents the results on the bias corrections of monthly and yearly precipitation for each station, regression and correlation of monthly precipitation data between the stations, and cumulative precipitation via the double mass curves for the warm (monthly temperature $>0{ }^{\circ} \mathrm{C}$ ) and cold seasons (monthly temperature $\left.<0{ }^{\circ} \mathrm{C}\right)$.

\subsection{Monthly data and corrections}

The monthly mean precipitation and bias corrections are illustrated in Fig. 2 for the northern group during the corresponding observation period (Table 1). In Fig. 2, the missing data percentages are also presented for each month. Barter Island had the lowest percentages of missing data, about $2 \%$ as a maximum monthly mean in December. The mean missing percentages for the Komakuk station was about $5 \%$ (in May), with the maximum month in July 1984 (16\%). For
Shingle Point, the mean missing values were $11 \%$ for both April and May, with the maximum (26\%) in April 1979. Given the small percentages of missing records, its impact is insignificant on monthly mean and yearly precipitation calculations. Figure 2 shows that annual precipitation cycle was centred on August, with an approximate maximum $P_{\mathrm{m}}$ around 40 to $80 \mathrm{~mm}$ between August and September. This maximum was coincident with the monthly mean maximum temperature in the area (around $10^{\circ} \mathrm{C}$ ).

For the Barter Island station in $\mathrm{AK}$, the corrections were variable through the months. The monthly corrections increased the $P_{\mathrm{m}}$ amount by 3-31 $\mathrm{mm}$ for snow to $4-9 \mathrm{~mm}$ for rain. The relative increases were $59-136 \%$ for snow and 20$41 \%$ for rain, with a monthly mean of $9 \mathrm{~mm}$ (or $76 \%$ ). The relative changes were usually large for months with low $P_{\mathrm{m}}$ and small for months with high precipitation. In other words, the monthly correction amounts did not always match the percentage changes; i.e. a small correction in a dry month can have a large percentage change.

It is important to note that gauge measurements at Barter showed the maximum precipitation in August, but the peak shifted to October due to the corrections; i.e. the mean monthly $P_{\mathrm{c}}$ in October were $98 \%$ (about $32 \mathrm{~mm}$ ) more than the $P_{\mathrm{m}}$ (Fig. 2). Closer examination of the monthly precipitation time series for Barter Island (Fig. 3) indicated that, for most of the years, October was the most significant contributor to the total annual (23\% for $P_{\mathrm{m}}$ and $22 \%$ for $P_{\mathrm{c}}$ ). However, there were some years in the study period with the maximum $P_{\mathrm{m}}$ in other months; for example, the highest $P_{\mathrm{m}}$ in 1982 was in September, as documented by Yang et al. (1998b). Climate data and analyses showed 


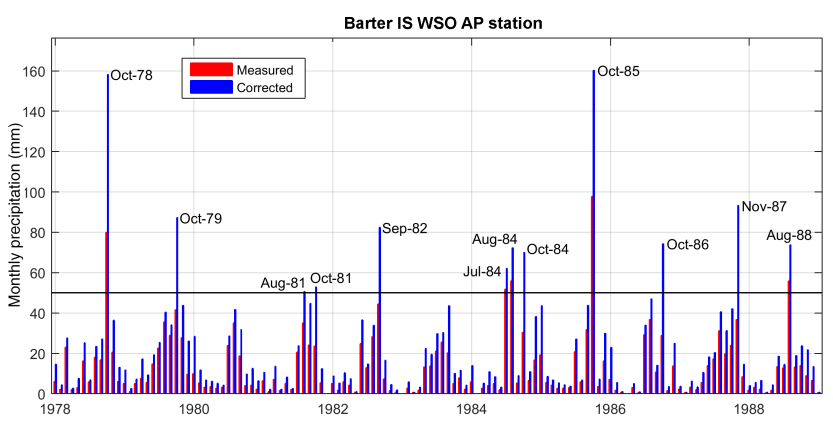

Figure 3. Monthly precipitation records at the Barter station during 1978-1988. The months with more than $50 \mathrm{~mm}$ (black line) are labelled.

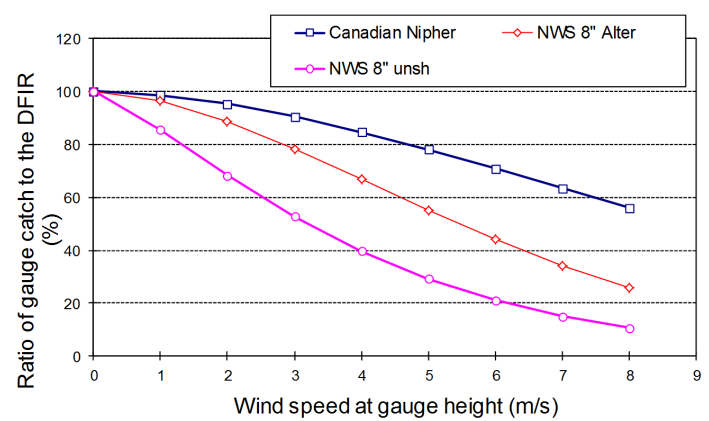

Figure 4. Comparison of the catch ratio of snowfall as a function of wind speed at gauge height for the Alter-shielded or unshielded NWS 8 in. standard gauge and the Canadian Nipher snow gauge. DFIR is the Double Fence Intercomparison Reference (Yang et al., 1998)

It was necessary to compare the correction result across the border in order to quantify the effect of biases in gauge observations on precipitation analyses, such as precipitation distribution and seasonal patterns. The mean snowfall corrections were about $96 \%$ for Barter Island in Alaska and around $22 \%$ for both Shingle Point and Komakuk stations in Yukon; while the rainfall corrections were approximately $32 \%$ for Barter and $7 \%$ for the two Yukon stations. Bias corrections also demonstrated a clear shift in the maximum precipitation timing for the Barter Island, but no change for the Yukon stations. This remarkable contrast across the border was caused mainly by the difference in gauge types and their catch efficiency. Many experimental studies have shown that the Canadian Nipher snow gauge catches more snowfall relative to the US gauge (Goodison et al., 1998; Yang et al., 1998b). For instance, the mean catch ratios for snowfall were about 40 and $85 \%$ for $4 \mathrm{~m} \mathrm{~s}^{-1}$ wind speed, respectively, for the NWS 8 in. unshielded and Nipher gauges (Fig. 4) (Yang et al., 1998b).

For the central group, the maximum and minimum $P_{\mathrm{m}}$ were in July and March for the Eagle station, respectively (Fig. 5). The corrections did not modify the timings of maximum and minimum amounts; they remained in July for the maximum $\left(P_{\mathrm{m}}=67 \mathrm{~mm}\right.$ and $\left.P_{\mathrm{c}}=70 \mathrm{~mm}\right)$ and in March for the minimum $\left(P_{\mathrm{m}}=3 \mathrm{~mm}\right.$ and $\left.P_{\mathrm{c}}=4 \mathrm{~mm}\right)$ precipitation. The correction increased the precipitation by $0.6-1.8 \mathrm{~mm}$ $(8-22 \%)$ for snow and $1-3 \mathrm{~mm}(5-10 \%)$ for rain, with a monthly mean correction of $1.7 \mathrm{~mm}(12 \%)$. The annual temperature cycle for Eagle showed warmer temperatures relative to the northern station, with the maximum of $16.2^{\circ} \mathrm{C}$ and above $0^{\circ} \mathrm{C}$ during April to mid-October. Eagle had lower wind speeds around $1 \mathrm{~m} \mathrm{~s}^{-1}$ (Fig. 5).

For Dawson station, precipitation was more homogeneous throughout months, varying from $10 \mathrm{~mm}$ in October to $50 \mathrm{~mm}$ in June. Another relative maximum occurs in January with $P_{\mathrm{m}}=38 \mathrm{~mm}$ (Fig. 5). The precipitation correction was small and fluctuated from 0.3 to $1 \mathrm{~mm}$ (or $2-4 \%$ ) for snow and $0.4-1.3 \mathrm{~mm}(3-4 \%)$ for rain. This small correction 

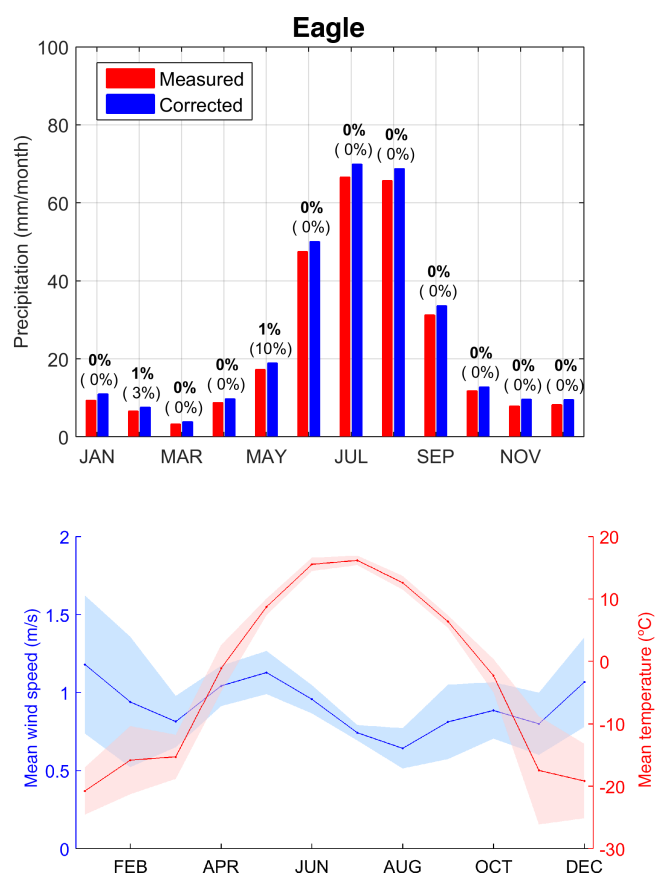
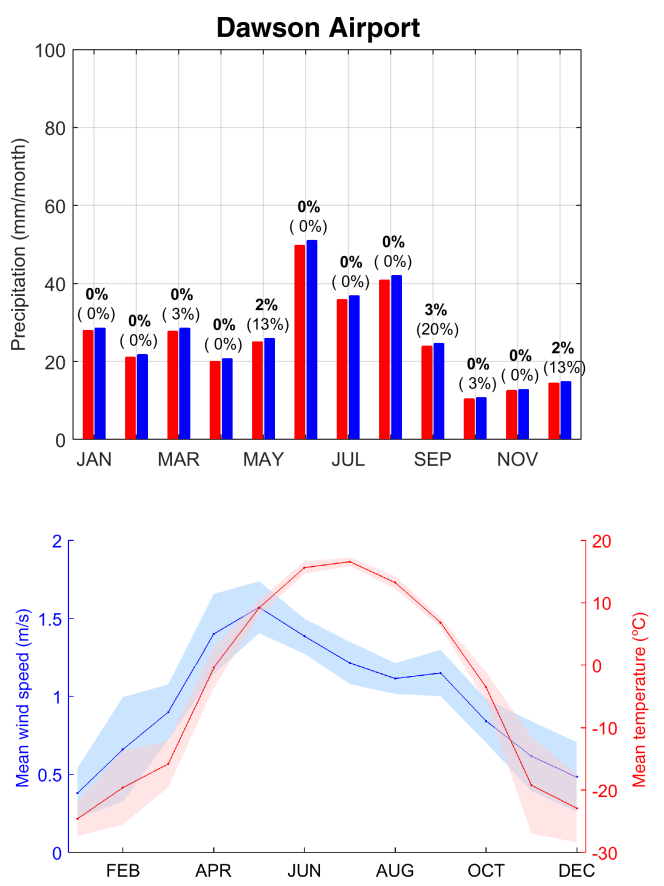

Figure 5. Monthly mean precipitation at two stations during 2006-2013 (upper panels) and corresponding monthly mean wind speed and air temperature (bottom panels). Shadows represent the $95 \%$ confidence interval for the temperature and wind speed. The percentages above the bars represent the missing data for the corresponding time step. The bold percentage is the monthly mean, and the one in the parentheses is the maximum missing value in the study period.

was due to the lower undercatch correction for the Nipher gauge, besides the warmer temperatures and lighter winds. The temperature annual amplitude was between $16^{\circ} \mathrm{C}$ in July and $-25^{\circ} \mathrm{C}$ in January, with temperatures above $0{ }^{\circ} \mathrm{C}$ from April to September. Wind speeds showed a clear annual cycle with the maximum in May $\left(1.6 \mathrm{~m} \mathrm{~s}^{-1}\right)$ and lighter winds in winter months, with the minimum in January $\left(0.4 \mathrm{~m} \mathrm{~s}^{-1}\right)$.

The temperature and wind conditions were similar between the Eagle and Dawson stations, with mean temperature around $1^{\circ} \mathrm{C}$ and wind speed of $1 \mathrm{~m} \mathrm{~s}^{-1}$. The missing data percentages were also similar for Eagle and Dawson stations: less than $3 \%$ for most months, with the maximum of $10 \%$ in May 2006 for Eagle and $20 \%$ in September 2009 for Dawson. The bias corrections were quite different, with the mean corrections of $16 \%$ for snow and $7 \%$ for rain at Eagle, and about 2 and $3 \%$ for both rain and snow at Dawson. Overall, the correction was 4 times greater at Eagle than that at Dawson. This discrepancy reflects again the catch difference between the US and Canadian standard gauges.

In order to understand the effect of precipitation bias corrections on regional climate around the $\mathrm{AK}-\mathrm{YK}$ border, it was useful to examine and compare the temperature and precipitation features between the northern and central regions. The monthly mean temperature threshold of $0{ }^{\circ} \mathrm{C}$ did not occur exactly at the same time among the two groups; the warm months (above $0{ }^{\circ} \mathrm{C}$ ) were between June and September in the north group and between April and September in the central group. Although both regions had similar mean minimum temperatures, around $-24^{\circ} \mathrm{C}$ and $-27^{\circ} \mathrm{C}$, the maximum temperature was considerably lower in the north part, with the average of $8^{\circ} \mathrm{C}$ in the north group vs. $16^{\circ} \mathrm{C}$ for the central region. Additionally the monthly mean wind speed was higher for the northern region, 4 vs. $1 \mathrm{~m} \mathrm{~s}^{-1}$. Therefore, because of the colder temperatures and higher winds in the northern region, the bias corrections were higher in the north relative to the central region.

\subsection{Yearly data and corrections}

The annual $P_{\mathrm{m}}$ and $P_{\mathrm{c}}$ time series for 11 years during 19781988 in the northern group is presented in Fig. 6. There were almost no missing data for the whole period, except $3 \%$ for 1978. At the Barter Island station in Alaska, the yearly $P_{\mathrm{m}}$ ranged from 114 to $211 \mathrm{~mm}$, with a long-term mean of $155 \mathrm{~mm}$. The mean annual corrections ranged from 67 to $138 \mathrm{~mm}$, with a long-term mean of $101 \mathrm{~mm}$ (or $65 \%$ ). The $P_{\mathrm{c}}$ records varied from 181 to $343 \mathrm{~mm}$. The maximum precipitation was in 1985 for both $P_{\mathrm{m}}$ and $P_{\mathrm{c}}(211$ and $343 \mathrm{~mm}$, respectively). The minimum precipitation was in 1983 for the $P_{\mathrm{m}}$ and $P_{\mathrm{c}}$ (114 and $181 \mathrm{~mm}$, respectively).

For Komakuk Beach station in Yukon, the $P_{\mathrm{m}}$ ranged from 103 to $306 \mathrm{~mm}$, with the missing data between 0 and $7 \%$ among the years. The bias corrections increased the precipitation by 13 to $45 \mathrm{~mm}$ (or 8-19\%). The long-term mean was 

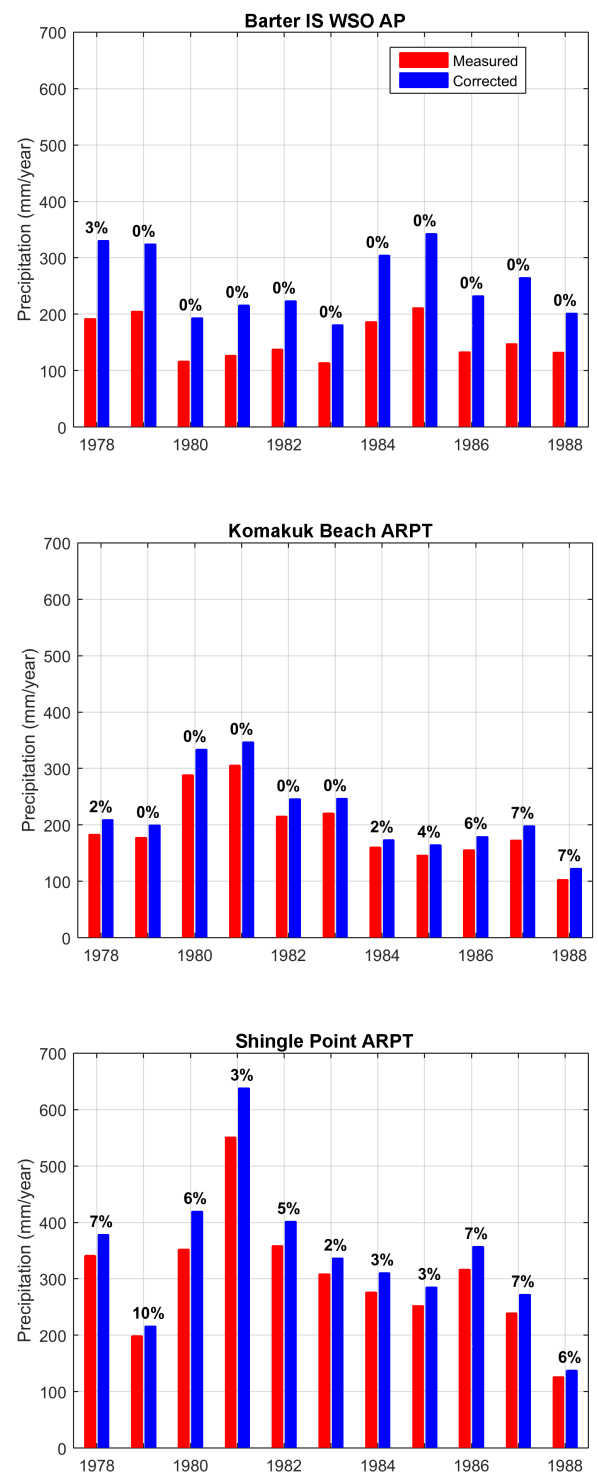

Figure 6. Annual precipitations during 1978-1988 for the three stations in the northern group across the border. The percentages above the bars represent the missing data for the corresponding year.

about $194 \mathrm{~mm}$ for $P_{\mathrm{m}}$ and $220 \mathrm{~mm}$ with the corrections. The maximum precipitation occurred in 1981: 306 and $347 \mathrm{~mm}$ for $P_{\mathrm{m}}$ and $P_{c}$, respectively. The minimum precipitation was in 1988 for both the $P_{\mathrm{m}}$ and $P_{\mathrm{c}}: 103$ and $123 \mathrm{~mm}$, respectively.

For Shingle Point station in Yukon, yearly $P_{\mathrm{m}}$ varied from 126 to $551 \mathrm{~mm}$ and the $P_{\mathrm{c}}$ ranged from 138 to $638 \mathrm{~mm}$. The mean annual total precipitation was about $302 \mathrm{~mm}$ for $P_{\mathrm{m}}$ and $341 \mathrm{~mm}$ after the corrections (change of $13 \%)$. The high and low extreme years were 1981 $\left(P_{\mathrm{m}}=551 \mathrm{~mm}, P_{\mathrm{c}}=638 \mathrm{~mm}\right)$ and $1988\left(P_{\mathrm{m}}=126 \mathrm{~mm}\right.$, $\left.P_{\mathrm{c}}=138 \mathrm{~mm}\right)$. Shingle station had missing data from $2 \%$ in 1983 to $10 \%$ in 1979 .

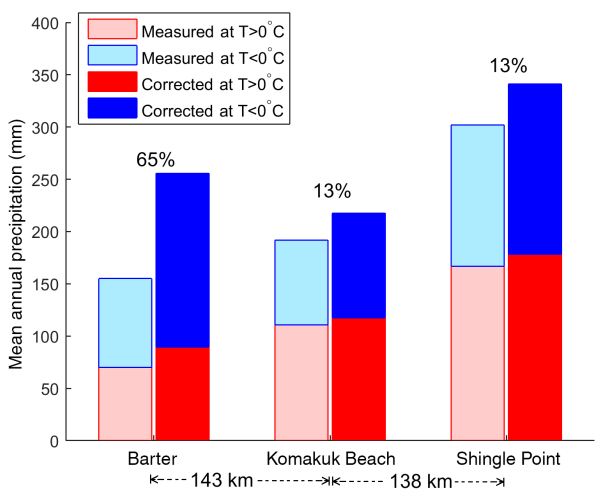

Figure 7. Mean annual (1978-1988) measured and corrected precipitation for cold $\left(T<0^{\circ} \mathrm{C}\right)$ and warm $\left(T>0{ }^{\circ} \mathrm{C}\right)$ months. The percentages are the changes from measured to corrected precipitation. The approximate horizontal distance between the stations is displayed at the bottom.

Figure 7 displays the mean annual precipitation in cold and warm seasons for the northern group. The gauge measurements showed annual values from $155 \mathrm{~mm}$ at Barter Island and $194 \mathrm{~mm}$ at Komakuk to $302 \mathrm{~mm}$ at Shingle Point, i.e. a strong precipitation increase from the west to the east, particularly between Komakuk Beach and Shingle Point. However, the corrected data $\left(P_{\mathrm{c}}\right)$ showed a different pattern (Fig. 7), i.e. higher precipitation at Barter than Komakuk, so the gradient across the border changed the sign and magnitude. This change was caused mainly by the high correction at the Barter station, particularly for snowfall data during the cold months (Fig. 2).

For the central group, the annual results are shown for 8 years (2006-2013) in Fig. 8. The $P_{\mathrm{m}}$ ranged from 66 to $391 \mathrm{~mm}$ at Eagle, and the bias corrections were 5-27 mm, correspondingly, which on average increase the total precipitation by $7 \%$. At Dawson, the $P_{\mathrm{m}}$ ranged from 158 to $333 \mathrm{~mm}$, and the adjustments were from 4 to $10 \mathrm{~mm}$, with an average increase in yearly precipitation by $3 \%$. The gauge data showed a slight increase $(12 \mathrm{~mm})$ of mean precipitation from west to east, i.e. slightly higher $P$ in Yukon relative to Alaska. This result is consistent with other studies (Simpson et al., 2002, 2005). The corrected data, on the other hand, suggest a smaller gradient $(1 \mathrm{~mm}$ ) across the border (Fig. 9). This change was mainly due to the higher corrections for the US 8 in. gauge at Eagle.

Similar to the monthly results, the northern stations exhibited higher yearly corrections for snowfall and rainfall measurements relative to the central group. This was because of higher winds in the northern stations, i.e. yearly mean wind speeds of $3.8 \mathrm{~m} \mathrm{~s}^{-1}$ in the north group and $1 \mathrm{~m} \mathrm{~s}^{-1}$ in the central group. This windy and snowy environment in the north produced higher wind loss for the snowfall measurements by the gauges, which were the largest errors in precipitation records in the high latitudes (Benning and Yang, 2005; Yang 

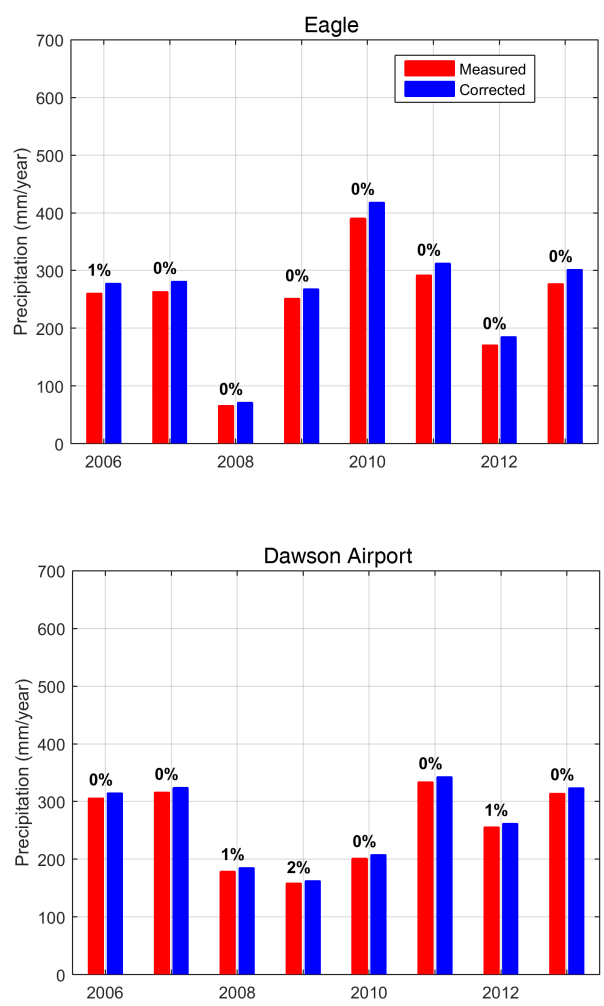

Figure 8. Annual precipitations during 2006-2013 for two stations in the central part of the $\mathrm{AK}-\mathrm{YK}$ border. The percentages above the bars represent the missing data for the corresponding year.

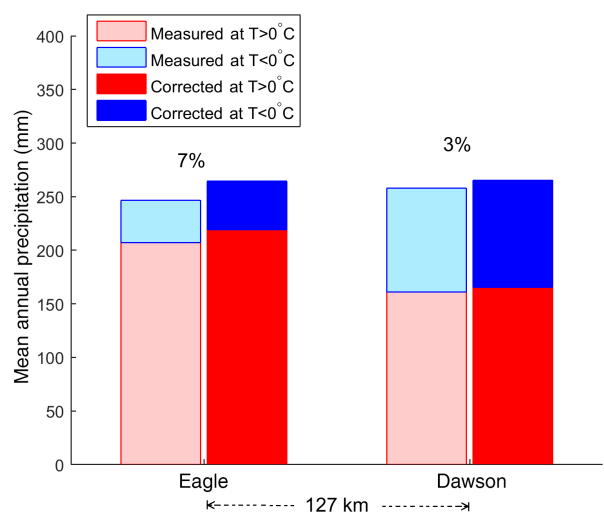

Figure 9. Mean annual (2006-2013) measured and corrected precipitation for cold $\left(T<0^{\circ} \mathrm{C}\right)$ and warm $\left(T>0{ }^{\circ} \mathrm{C}\right)$ months. The percentages are the change from measured to corrected precipitation. The approximate horizontal distance between the stations is displayed at the bottom.

and Ohata, 2001; Yang et al., 1998b). It is important to note that gauge-measured and bias-corrected data showed different pattern in seasonal and yearly precipitation in the northern region. In other words, bias corrections of gauge measurements alter the precipitation gradient in the northern areas; this change was mainly due to the difference in the catch
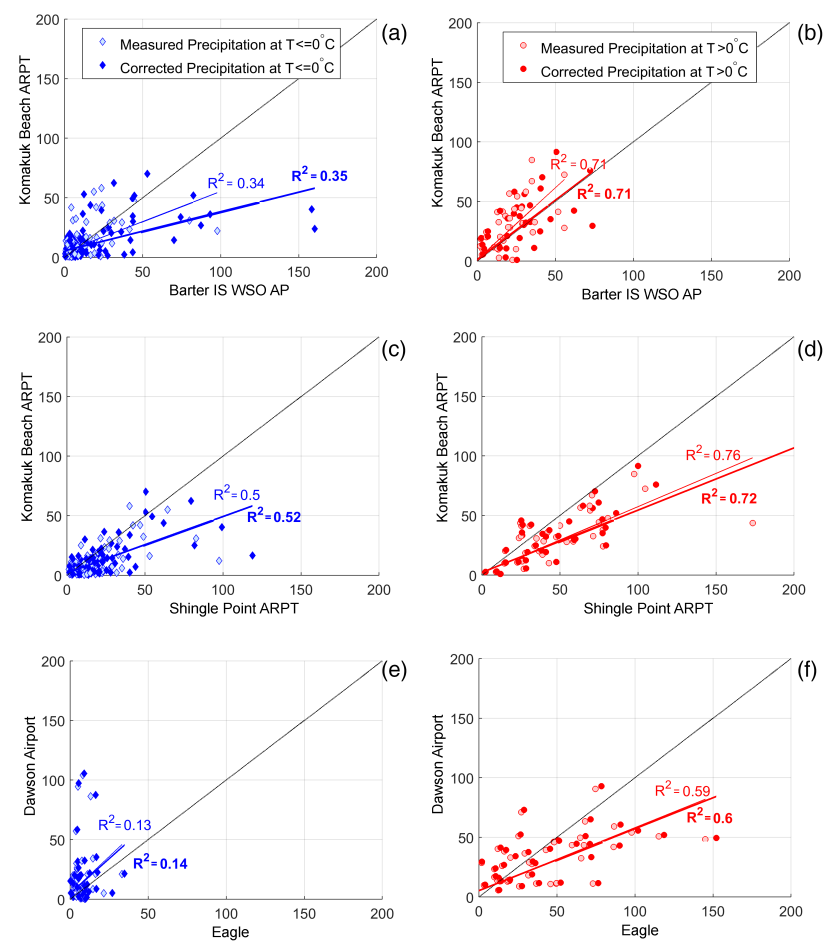

Figure 10. Scatter plots between station pairs for the measured and corrected precipitation $(\mathrm{mm})$. The red colour shows warm months and the blue represents the cold months. (a) and (b) - Barter and Komakuk comparison across the border; the highest corrected values for Barter (AK) are labelled with the date to compare with Fig. $4 \mathrm{c}$ and $\mathrm{d}-$ Komakuk and Shingle Point comparison within Canada. (e) and (f) - Eagle vs. Dawson across the border for the central group.

efficiency between the US and Canadian standard gauges. The corrections for the US gauge snow measurements were much higher than the Canadian gauge, particularly in the cold and windy coastal regions.

\subsection{Regression analysis of monthly data}

The scatter plots of corresponding monthly precipitation for the two stations across the border and between the two Yukon stations in Canada are illustrated in Fig. 10. For the cold season (Fig. 10a), the gauge data showed more snowfall at Barter for most years. Regression analysis suggested a weak relationship, with $R^{2}=0.34$. The corrected data showed a similar relationship, but a shift in the regression line, indicating a greater precipitation difference over the cold season across the border. For the warm season (Fig. 10b), the gauge data showed higher precipitation at the Komakuk station, and the regression suggested a much stronger relationship. The corrected data revealed a closer relationship between these two stations, proposing a smaller gradient for the warm months. 
The scatter plot between the two stations in the Yukon Territory showed higher precipitation at Shingle Point for both cold and warm seasons. It also gave another point of view about the effect of the correction in this area. Relative to the cold months (Fig. 10c), the corrections were smaller for the warm months (Fig. 10d), and correlation improved $\left(R^{2}=0.72-0.76\right)$. However, the relationship did not change much in both cases between the measured and corrected data. This was because of the very small amount of corrections for the lower wind conditions and higher catch efficiency of the Canadian Nipher gauge.

For the central group, the scatter plot between Eagle and Dawson stations illustrated a clear difference in precipitation amount for the cold and warm months (Fig. 10e-f). The cold months showed more precipitation at Dawson, particularly for the wettest events, while Eagle did not show any comparable amount. The correlation was weak and insignificant $\left(R^{2}=0.13\right)$. The shift in the fit line between measured and corrected data was also very small. The warm months showed low precipitation at Dawson: a different pattern from the cold months. The regression was better, $R^{2}=0.59$ with a smaller shift due to the corrections.

Overall, we obtained consistent results among the Alaska and Yukon stations. The correlations were higher in warm months $\left(R^{2}=0.58\right.$ to 0.76$)$ and lower for the cold season ( $R^{2}$ between 0.13 and 0.52 ). This result may suggest that the rainfall was more homogeneous over the regions in summer, and greater difficulty and errors in snowfall measurements during the cold months.

\subsection{Cumulative precipitation via DMCs}

The DMC plot for Barter Island and Komakuk Beach showed more $P_{\mathrm{m}}$ at Komakuk than Barter (Fig. 11a). The bias corrections led to a shift of the relationship with a significant increase in the total precipitation amount at Barter. Relatively, the total cumulative precipitation for Barter Island increased by $65 \%$ after the correction and by $14 \%$ at Komakuk. The difference between the two stations at the last cumulative point (December 1988) is $426 \mathrm{~mm}$ for $P_{\mathrm{m}}$ and $393 \mathrm{~mm}$ for $P_{\mathrm{c}}$. This shift represented a modification in the precipitation difference between these stations, i.e. a change in the gradient's direction (Fig. 7).

The comparison of cumulative precipitation values between Shingle Point and Komakuk, both in Yukon, is illustrated in Fig. 11b. Shingle Point showed more cumulative precipitation at the end of the period $\left(P_{\mathrm{m}}=3322 \mathrm{~mm}\right.$ vs. $P_{\mathrm{m}}=2115 \mathrm{~mm}$ for Komakuk). Although the relationship was more homogeneous between these stations, there was a break in the records around $1300 \mathrm{~mm}$ for Komakuk, maybe associated with changes in instruments or sensors. Examination of the station history and information revealed an anemometer issue around the critical time that was fixed by August 1980. This may affect wind data and thus the cor-

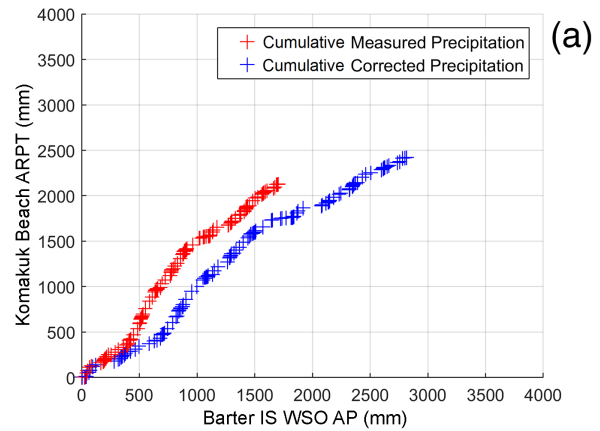

(a)

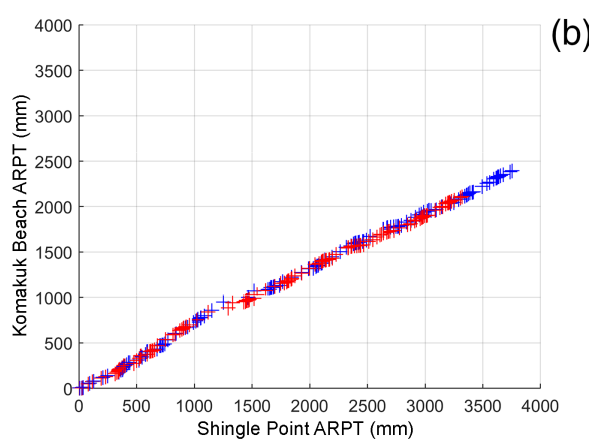

(b)

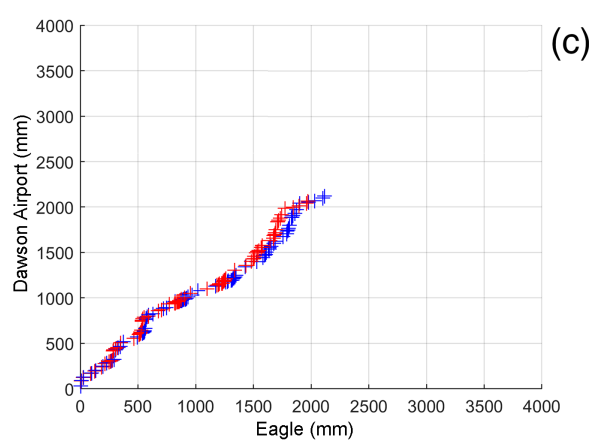

Figure 11. Double mass curves between station pairs. The red colour shows the warm months, and blue represents the cold months. The top and the central plots compare the stations for the northern group, and the bottom one is the central station comparison across the border.

rected precipitation values. Both stations showed increases in total cumulative precipitation by $13 \%$.

The central stations showed a greater amount of $P_{\mathrm{m}}$ in Dawson $(2065 \mathrm{~mm})$ than in Eagle $(1973 \mathrm{~mm})$ over the study period. Bias corrections changed the total precipitation by 3 and $7 \%$ for Dawson and Eagle, respectively, resulting in a shift in the DMC (Fig. 11c), particularly for the last period of time, to $2123 \mathrm{~mm}$ in Dawson and to $2116 \mathrm{~mm}$ in Eagle. This shift also represented a slightly smaller precipitation difference between the two stations. During the 8 years, the cumulative difference decreased from 92 to $7.3 \mathrm{~mm}$.

In summary, the DMC for measured and corrected precipitation showed that the main change was due to the differ- 
ence in their corrections (Fig. 11); the north stations showed a greater change compared with the central group. The $P_{\mathrm{c}}$ showed in all the cases a smaller precipitation difference between the two countries. This smaller difference led to a decrease in the precipitation gradient across the border. This result implies that existing precipitation climate maps and information derived from gauge measurement without bias corrections may overestimate the precipitation gradient in these regions. This overestimation will affect regional climate and hydrology analyses.

\section{Summary and discussion}

This study documents and quantifies the inconsistency in precipitation measurements in the northern and central regions of Alaska/Yukon, with a focus on station pairs across USACanada border. The monthly bias corrections show large errors in the gauge records due to the windy and cold environment in the northern areas of Alaska and Yukon. The corrections for gauge undercatch increase the snowfall by $136 \%$ in January for Barter Island station in Alaska. For the Yukon stations, the increase is about $31 \%$ in January and $4 \%$ in July. These represent an annual mean loss of $81 \mathrm{~mm}(101 \%)$ in snowfall and $20 \mathrm{~mm}(29 \%)$ of rain at Barter, while at Shingle Point and Komakuk Beach in Yukon the corrections are, on average, about $25 \mathrm{~mm} \mathrm{(21 \% )} \mathrm{for} \mathrm{snow} \mathrm{and} 8 \mathrm{~mm}(6 \%)$ for rain. For Eagle (AK) and Dawson (YK) stations in the central region, the bias corrections are small. The monthly corrections range from 2 to $22 \%$ in winter and from 3 to $10 \%$ in summer months.

On the annual scale, Barter Island station in AK shows a yearly mean correction of around $65 \%, 5$ times greater than the correction at Shingle Point and Komakuk Beach (13 and $14 \%$ ) in Canada. In the central region, Eagle station shows an increase by $7 \%$, meanwhile for Dawson the increase is only $3 \%$. Thus, the bias correction for Alaska is twice that of the Yukon stations. Relative to the northern region, these corrections are small mainly due to warmer temperatures and lower winds in the central region. These results clearly demonstrate that bias corrections may affect the spatial distribution of precipitation across the border.

Regression analyses of the monthly data show small changes in the relationship due to the bias corrections. The most evident change in the regression is between Barter Island and Komakuk Beach for both warm and cold seasons. The rest of the scatter plots, for Komakuk BeachShingle Point and Eagle-Dawson, do not show any appreciable change as the result of the bias corrections. There is a stronger precipitation correlation for the warm months (mainly rainfall) than for the cold month (mainly snowfall) for all the station pairs. The cold months seem to have greater precipitation variability across the regions.

The double mass curve analyses demonstrate a significant change in the precipitation accumulation and difference between the two stations across the AK-YK border for the northern region, little changes for the two stations in Yukon, and a smaller change in the central group. These changes, caused by gauge catch efficiency, alter the precipitation difference, resulting in a smaller and inverted precipitation gradient across the border in the northern region. The DMC is a useful tool for evaluating the consistency of observation records over space and time (Searcy and Hardison, 1960). Although in this work the DMC has not been constructed against a reference station, the results clearly show some breaks on the slope and gaps in the curves, indicating changes in precipitation relationship across the border that could be caused by any of the two stations. This information provides the timing when significant changes occurred in the precipitation regime. Detailed metadata and information for the stations/networks are necessary to understand the changes in precipitation observations and to improve the homogenization of the precipitation records over the high latitudes.

This study shows similar monthly $P_{\mathrm{m}}$ across the north border region and higher $P_{\mathrm{m}}$ in Yukon than Alaska over the central region. This result is similar to other studies (Serreze and Hurst, 2000; Simpson et al., 2005). After the bias corrections, precipitation patterns across the border changed, i.e. higher precipitation in Barter than Komakuk, or, in other words, an inverted gradient across the borderline. Over the central region, the measured mean annual precipitation is slightly higher in Yukon than Alaska, which is also consistent with Simpson et al. (2002, 2005). Our results suggest that the gradient between the central pair of stations becomes smaller after the bias correction. This discrepancy should be taken into account when using the precipitation data across the national borders for regional climate and hydrology investigations.

Missing data may affect regional precipitation analyses. In this study, we calculated the missing data percentages for all stations during the corresponding study periods and set up a threshold of $30 \%$ to exclude those months with higher missing values from monthly precipitation calculations. We compared the precipitation amounts with and without the application of the threshold. The results do not show any significant changes in the differences of gauge-measured annual mean precipitation across the border, although this filter affected annual precipitation in certain years. For instance, the northern station pair (Barter and Komakuk stations) has missing value of $32 \%$ in July 1987. Calculations of yearly precipitation for 1987 with and without this month show 16 and $10 \%$ difference at Komakuk and Barter Island stations, respectively. Over the study period of 11 years, the annual mean bias correction percentages remain the same $65 \%$ in Barter and $13 \%$ in Komakuk) with or without the missing months. The mean annual decrease in bias correction amounts after the consideration of missing data is about $1-3 \%$ in the northern region. This analysis suggests that the effect of missing data for our study is not significant, particularly with the application of a $30 \%$ missing threshold. More efforts are needed to further examine the issues of missing records in climate analyses. 
Classification of precipitation types is the first step for the bias corrections of gauge records. It is also important for climate change analyses over the cold regions. Leeper et al. (2015), in comparison of USCRN with the COOP station network precipitation measurements, averaged the USCRN hourly temperature data during precipitation periods into an event mean and used it to group precipitation events into warm (mean temperature $>5^{\circ} \mathrm{C}$ ), near-freezing (mean temperature between 0 and $5^{\circ} \mathrm{C}$ ), and freezing (mean temperature $<0^{\circ} \mathrm{C}$ ) conditions. Yang et al. (2005) used the daily mean air temperature to estimate precipitation types (snow, mixed, and rain) when this information was not available for the northern regions. In this study, monthly mean temperatures have been used to determine the warm months (mainly for rain) and cold months (mainly for snow). Mixed precipitation has not been classified separately. This approach is reasonable for our analysis to focus on the inconsistency in the monthly and yearly $P_{\mathrm{m}}$ records across the border. Data collections and analyses on shorter timescales, such as daily or hourly steps, are expected to produce better results, since temperatures vary throughout the days in a month, particularly in the spring and fall seasons. Automatic sensors will also be important to decide precipitation types at the operational and research networks.

The bias-corrected precipitation data set developed by Yang et al. (2005) has been used for this analysis. The corrections have been done systematically on a daily timescale that affects the daily $P_{\mathrm{m}}$ time series. This analysis focuses on the results of monthly and yearly precipitation data and quantifies the changes in precipitation pattern across the AKYK border. Careful analyses of available daily measured $P_{\mathrm{m}}$ and corrected $P_{\mathrm{c}}$ data are necessary, since in the northern regions with low precipitation in winter the bias corrections can easily increase the daily $P_{\mathrm{m}}$ by a factor of up to 4-5 (Benning and Yang, 2005; Kane and Stuefer, 2015; Yang et al., 1998b, 2005). This means that extreme precipitation events have been very likely and seriously underestimated by using the gauge records without any bias corrections. The consequence is certainly significant for climate regime and change investigations. To fill this knowledge gap, our efforts are underway to examine the daily corrections, particularly on the windy and heavy-precipitation days, and to document the possible underestimation of precipitation extremes over the large northern regions.

Automation of the meteorological observation networks and instruments has been a trend over the past few decades around the world, including both developed and developing nations. There is a large variety of automatic gauges currently used for precipitation measurements at the national networks (Nitu and Wong, 2010). These gauges differ in the measuring system, orifice area, capacity, sensitivity, and configuration. The variation in automatic gauges is much greater relative to the manual standard gauges (Goodison et al., 1998; Sevruk and Klemm, 1989). As demonstrated by Yang et al. (2001) and this study, the use of different instruments and configu- rations significantly affect the accuracy and consistency of regional precipitation data. Fortunately, the Geonor gauge has recently been chosen and used at both the US Climate Reference Network and the Surface Weather and Climate Network (SWCN) in Canada. This may reduce the inconsistency in precipitation measurements across the USA-Canada border, although the double and single Alter windshields have been installed with the Geonor gauges in the USA and Canada, respectively.

Finally, it is important to emphasize that automatic gauges also significantly under-catch snowfall (Wolff et al., 2015), and bias corrections are necessary in order to obtain reliable precipitation data for the cold regions and seasons. The WMO SPICE project aims to examine the performance of automatic gauges and instruments for snowfall observations in various climate conditions. It has tested many different automatic gauges, including the Geonor gauge, at more than 20 field sites around the globe (Nitu et al., 2012; Rasmussen et al., 2012; Wolff et al., 2015). The results of this project will be very useful to improve precipitation data quality and regional climate analyses, including the border regions between the USA and Canada.

Acknowledgements. The authors gratefully acknowledge the support from the Global Institute of Water Security at the University of Saskatchewan and Environment Canada.

Edited by: M. Wolff

\section{References}

Benning, J. and Yang, D.: Adjustment of Daily Precipitation Data at Barrow and Nome Alaska for 1995-2001, Arct. Antarct. Alp. Res., 37, 276-283, doi:10.1657/15230430(2005)037[0276:AODPDA]2.0.CO;2, 2005.

Goodison, B. E.: Compatibility of Canadian snowfall and snow cover data, Water Resour. Res., 17, 893-900, doi:10.1029/WR017i004p00893, 1981.

Goodison, B. E., Louie, P. Y. T., and Yang, D.: WMO solid precipitation measurement intercomparison, WMO/TD 872, World Meteorological Organization, Geneva, Switzerland, 1998.

Groisman, P. Y. and Easterling, D. R.: Variability and Trends of Total Precipitation and Snowfall over the United States and Canada, J. Climate, 7, 184-205, doi:10.1175/15200442(1994)007<0184:VATOTP>2.0.CO;2, 1994.

Jones, S. H. and Fahl, C. B.: Magnitude and Frequency of Floods in Alaska and Conterminous Basins of Canada, Water-Resources Investigations Report 93-4179, U.S. Geological Survey, Anchorage, Alaska, 1994.

Kane, D. L. and Stuefer, S. L.: Reflecting on the status of precipitation data collection in Alaska: a case study, Hydrol. Res., 46, 478-493, doi:10.2166/nh.2014.023, 2015.

Leeper, R. D., Rennie, J., and Palecki, M. A.: Observational Perspectives from US Climate Reference Network (USCRN) and Cooperative Observer Program (COOP) Network: Temperature 
and Precipitation Comparison., J. Atmos. Ocean. Tech., 32, 703$721,2015$.

Legates, D. R. and Willmott, C. J.: Mean seasonal and spatial variability in gauge-corrected, global precipitation, Int. J. Climatol., 10, 111-127, doi:10.1002/joc.3370100202, 1990.

Manson, G. K. and Solomon, S. M.: Past and future forcing of Beaufort Sea coastal change, Atmos. Ocean, 45, 107-122, doi:10.3137/ao.450204, 2007.

Mekis, É. and Brown, R.: Derivation of an adjustment factor map for the estimation of the water equivalent of snowfall from ruler measurements in Canada, Atmos. Ocean, 48, 284-293, doi:10.3137/AO1104.2010, 2010.

Mekis, É. and Vincent, L. A.: An Overview of the Second Generation Adjusted Daily Precipitation Dataset for Trend Analysis in Canada, Atmos. Ocean, 49, 163-177, doi:10.1080/07055900.2011.583910, 2011.

Metcalfe, J. R. and Goodison, B. E.: Correction of Canadian winter precipitation data, in Proc. 8th Symp. on Meteorological Observations and Instrumentation, Amer. Meteor. Soc., Anaheim, CA, 338-343, USA, 1993.

Nitu, R. and Wong, K.: CIMO Survey on national summaries of methods and instruments for solid precipitation measurement at automatic weather stations, World Meteorological Organization (WMO), Geneva, Switzerland, 2010.

Nitu, R., Rasmunssen, R., Baker, B., Lanzinger, E., Joe, P., Yang, D., Smith, C., Roulet, Y. A., Goodison, B., Liang, H., Sabatini, F., Kochendorfer, J., Wolff, M., Hendrikx, J., Vuerich, E., Lanza, L., Aulamo, O., and Vuglinsky, V.: WMO intercomparison of instruments and methods for the measurement of solid precipitation and snow on the ground: organization of the experiment, World Meteorological Organization (WMO), Brussels, Belgium, 2012.

Rasmussen, R., Baker, B., Kochendorfer, J., Meyers, T., Landolt, S., Fischer, A. P., Black, J., Thériault, J. M., Kucera, P., Gochis, D., Smith, C., Nitu, R., Hall, M., Ikeda, K., and Gutmann, E.: How well are we measuring snow? The NOAA/FAA/NCAR Winter Precipitation Test Bed, B. Am. Meteorol. Soc., 93, 811-829, doi:10.1175/BAMS-D-11-00052.1, 2012.

Sanderson, M.: Notes and correspondence: A comparison of Canadian and United States Standard Methods of Measuring Precipitation, J. Appl. Meteorol., 14, 1197-1199, 1975.

Searcy, J. and Hardison, C.: Double-Mass Curves, United States Department of the Interior, Washington DC, USA, 1960.

Šeparović, L., Alexandru, A., Laprise, R., Martynov, A., Sushama, L., Winger, K., Tete, K., and Valin, M.: Present climate and climate change over North America as simulated by the fifthgeneration Canadian regional climate model, Clim. Dynam., 41, 3167-3201, doi:10.1007/s00382-013-1737-5, 2013.

Serreze, M. C. and Hurst, C. M.: Representation of mean Arctic precipitation from NCEP-NCAR and ERA reanalyses, J. Climate, 13, 182-201, doi:10.1175/15200442(2000)013<0182:ROMAPF>2.0.CO;2, 2000.

Sevruk, B. and Klemm, S.: Types of standard precipitation gauges, in Proceedings of International Workshop on Precipitation Measurement, WMO/IAHS/ETH, vol. 227236, St. Moritz, Switzerland, 1989.
Simpson, J. J., Hufford, G. L., Fleming, M. D., Berg, J. S., and Ashton, J. B.: Long-term climate patterns in Alaskan surface temperature and precipitation and their biological consequences, IEEE T. Geosci. Remote, 40, 1164-1184, doi:10.1109/TGRS.2002.1010902, 2002.

Simpson, J. J., Hufford, G. L., Daly, C., Berg, J. S., and Fleming, M. D.: Comparing maps of mean monthly surface temperature and precipitation for Alaska and adjacent areas of Canada produced by two different methods, Arctic, 58, 137-161, 2005.

Wolff, M. A., Isaksen, K., Petersen-Øverleir, A., Ødemark, K., Reitan, T., and Brækkan, R.: Derivation of a new continuous adjustment function for correcting wind-induced loss of solid precipitation: results of a Norwegian field study, Hydrol. Earth Syst. Sci., 19, 951-967, doi:10.5194/hess-19-951-2015, 2015.

Yang, D. and Ohata, T.: A Bias-Corrected Siberian Regional Precipitation Climatology, J. Hydrometeorol., 2, 122-139, doi:10.1175/1525-7541(2001)002<0122:ABCSRP>2.0.CO;2, 2001.

Yang, D. and Simonenko, A.: Comparison of Winter Precipitation Measurements by Six Tretyakov Gauges at the Valdai Experimental Site, Atmos. Ocean, 52, 39-53, doi:10.1080/07055900.2013.865156, 2013.

Yang, D., Goodison, B. E., Metcalfe, J. R., Golubev, V. S., Elomaa, E., Gunther, T., Bates, R., Pangburn, T., Hanson, C. L., Emerson, D., Copaciu, V., and Milkovic, J.: Accuracy of tretyakov precipitation gauge: Result of WMO intercomparison, Hydrol. Process., 9, 877-895, doi:10.1002/hyp.3360090805, 1995.

Yang, D., Goodison, B. E., Metcalfe, J. R., Golubev, V. S., Bates, R., Pangburn, T., and Hanson, C. L.: Accuracy of NWS 8" standard nonrecording precipitation gauge: Results and application of WMO intercomparison, J. Atmos. Ocean. Tech., 15, 54-68, doi:10.1175/1520-0426(1998)015<0054:AONSNP>2.0.CO;2, 1998a.

Yang, D., Goodison, B. E., Ishida, S., and Benson, C. S.: Adjustment of daily precipitation data at 10 climate stations in Alaska: Application of World Meteorological Organization intercomparison results, Water Resour. Res., 34, 241-256, doi:10.1029/97WR02681, 1998b.

Yang, D., Ishida, S., Goodison, B. E. and Gunther, T.: Bias correction of daily precipitation measurements for Greenland, J. Geophys. Res., 104, 6171, doi:10.1029/1998JD200110, 1999.

Yang, D., Goodison, B., Metcalfe, J., Louie, P., Elomaa, E., Hanson, C., Golubev, V., Gunther, T., Milkovic, J., and Lapin, M.: Compatibility evaluation of national precipitation gage measurements, J. Geophys. Res., 106, 1481-1491, doi:10.1029/2000JD900612, 2001.

Yang, D., Kane, D., Zhang, Z., Legates, D. and Goodison, B.: Bias corrections of long-term (1973-2004) daily precipitation data over the northern regions, Geophys. Res. Lett., 32, L19501, doi:10.1029/2005GL024057, 2005.

Zhao, K., Stadnyk, T., Koenig, K., and Crawford, J.: Better Precipitation Product over the Red River Basin, B.Sc. thesis, University of Manitoba, Winnipeg, Manitoba, Canada, available at: http://watflood.ce.umanitoba.ca/Publication.html (last access: 18 December 2015), 2010. 